\title{
Climbing Performance Analysis of Radial Tire on Wet Pavement
}

\author{
Gang Cheng ${ }^{1, a *}$, Shihao Zhang ${ }^{1, b}$, Yunjiang $\mathrm{Li}^{1, \mathrm{c}}$, Guoqun Zhao ${ }^{2}$, \\ Qiang Cheng ${ }^{3}$, Zhonglei Wang ${ }^{1}$ and Na Liu ${ }^{1}$ \\ ${ }^{1}$ School of mechanical and electronic engineering, Key Laboratory of Mechanical Engineering \& \\ Innovation Technology, Shandong Jianzhu University, Jinan250101, China \\ ${ }^{2}$ Engineering Research Center fo $r$ Mould \& Die, Shandong University , Jinan 250061, China \\ ${ }^{3}$ School of Mechanical and Automotive engineering, Qilu University, Jinan 250353, China \\ ${ }^{a *}$ chenggang117@126.com, b1464844544@qq.com, cliyunjiang38@126.com
}

\begin{abstract}
Keywords: Wet pavement, grade ability, contact deformation, critical velocity.
Abstract. Application of the Hydromechanics and the Momentum theorem, the driving critical velocity on wet pavement formula is established. It presents the tire-water-slope finite element modeling process. Through comparing the deformation rule of the loaded tire on horizontal ground and slope ground, analyses the tire grade ability on wet ground, and concludes the relationship between the tire load and the angle. Meanwhile compares the contact force change progress with the increased velocity when driving on the $\alpha=3^{\circ}$ and $\alpha=8^{\circ}$ pavement. And it estimates the critical velocity on wet slope..
\end{abstract}

\section{Introduction}

China has many mountain heavy-hilly areas. Mountain areas account for over $70 \%$ of the total area and highways in mountain areas also account for large proportion in China highway network. Domestic studies therefore pay more attention on climbing performances of automobiles. Yao et al.[1] studied the effects of torque, power and maximum rotate speed of motor upon the tractive performance of pure electric vehicles, such as the maximum speed, climbing performance and accelerative performance. Li et al.[2] set up a virtual prototype model about of the tracked vehicle by the RecurDyn software , the process of climbing grade is simulated on the hard ground, clayey soil, heavy clay and dry sand. Cho et al.[3] analysed the tire hydroplaning by generally coupling an Eulerian finite volume method and an explicit agrangian finite element method. the preset tire slip ratio on the wet road is maintained by controlling the tire angular velocity. Oh et al.[4] developed an finite difference method to solve Navier-Stokes and continuity equations and to obtain the pressure distribution around a tire with the inertial and viscous effects of water taken into account. This simulation methodology was applied to a straight-grooved tire, and its hydroplaning speed was finally determined for a water depth of $5 \mathrm{~mm}, 10 \mathrm{~mm}, 15 \mathrm{~mm}$ and $20 \mathrm{~mm}$. Kumar et al.[5] simulated two extreme conditions of tire hydroplaning i.e. when the tire is completely rolling ( $0 \%$ slip) and a completely locked tire (100\% slip), and the analyses showed that the hydroplaning risk associated with the locked tire is more than the rolling tire.

An automobile running on wet slope pavement tends to incur hydroplaning. Tire hydroplaning is that when an automobile is running at a high speed on the pavement covered with water flow, the effect of water flow cannot be removed in whole or removed, giving rise to a pressure that floats the tire and the automobile is technically running on the water flow. The fiction coefficient between tread and pavement will be significantly reduced if an automobile is running on wet slop surface, especially in case of tire speed exceeding a certain speed limit. The dynamic pressure of water flow will cause the tire losing its driving force and braking force completely, which directly threats personal safety of passengers and the driver[6]. Therefore, it is of important practical significance and guiding role to study climbing performances of automobiles on wet pavements.

The study on climbing performances of automobile tire on wet pavement in this paper focuses on numerical analysis. A 3D finite element climbing simulation model of tire-water flow is established 
to analyze climbing performances of the radial tire on pavements covered with water flow. In addition, compare the deformation rules of radial tires on slopes of different angles and predict the critical hydroplaning speed.

\section{Finite element tire-pavement-water flow modeling}

Owing to the complex structure of tire and material nonlinearity, tire modeling takes a great effort that gives rise to numerous inconveniences to tire structure and performance analyses. To achieve high-efficient and automatic finite element modeling and analysis of tire, the finite element model parametric study of tire includes not only numerical parameterization of structure dimension geometrically but also some other parameterization processing measures such as boundary conditions and loads[7], etc.

\section{Automobile tire modeling}

Tire has complex structure that it needs to be reasonably simplified in the course of finite element modeling to acquire a simplified tire structure to the maximum extent under the condition of maintaining simulation precision, for example: ignoring some fine structures not affecting simulation analysis, combining parts made of same materials and conversion of materials and structures when they share the same effects. What shall be noted is that cord fabric, belted layer and carcass are composite materials. Calculate basic calculation parameters based on the empirical formula of classic mesomechanicsby referring to the structural theories of composite materials [8]. In the meantime, the issue of element mesh generation also needs to consider during modeling. The compacter the element mesh generation, the more time it takes to computing for a CPU, the better the quality of an element and the matrix tends to convergence more. Therefore, factors of all respects including computing time, mesh quality and simulation level, etc. shall be taken into account for tire modeling. In the finite element tire model in this paper, all tire parts of other materials use continuous solid element representation other than the rim using shell and thin element.

\section{Slope pavement modelling}

The pavement angle in this paper mainly refers to longitudinal slope, which means the longitudinal slope value adopted as per factors of highway classification and natural conditions in design of longitudinal slope ( Fig.1 ). Generally, the safe traffic pavement slope of common highways in China shall not exceed 10 degrees (namely $\alpha<10^{\circ}$ ) limited by topographic conditions and other exceptional circumstances. In the course of finite element modeling of pavement simulation, it is to use the solid unit of Lagrange rigid parameter with the slant angle of $\alpha$ to simulate the pavement on which automobiles are running.

\section{Water flow modelling and treatment of overall model}

It is important to choose water flow modeling with caution as the simulation course involves tire hydroplaning. In this paper, the viscosity and water velocity of the flow are ignored. The water flow uses an 8-node solid element representation. It is the solid ground under of rigid parameter to ensure the control on degree of freedom downward. At the same time, a thick air layer is defined above the water flow facilitating water scattering when thread pattern drains away water( Fig.2). To ensure the fluid-structure interaction between thread pattern and water flow lessen calculations to the largest extent, detailing treatment can be given to the mesh of contact field of water while other parts can use larger meshes.

The tire deformation and fluid analysis will be analyzed respectively using Finite Element Method (FEM) and Finite Volume Method (FVM), and the interaction between them shall be treated with general interaction algorithm[9]. Dytran finite element software is used in this paper for simulation computing. The established model is shown in the figure below.

\section{Influence of running velocity on slope climbing}

As shown in the above force analysis and numerical simulation that, the angle influences contact performances of automobile tires and contact forces between tire and ground, thus directly influences 
climbing performances of tire during running. The Fig. 3 gives the change rules of contact forces between ground and tire as the increase of automobile when the automobile tire runs under $5000 \mathrm{~N}$ vertical loads on hydroplaning pavements with angles of $3^{\circ}$ and $8^{\circ}$ respectively.

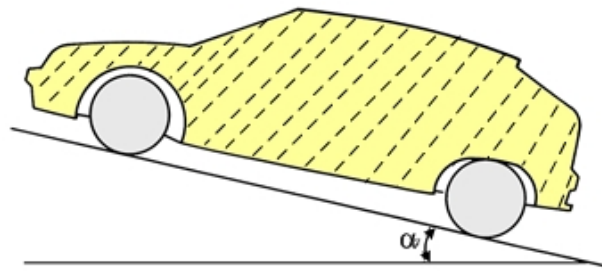

Fig.1 The diagram of slope angle

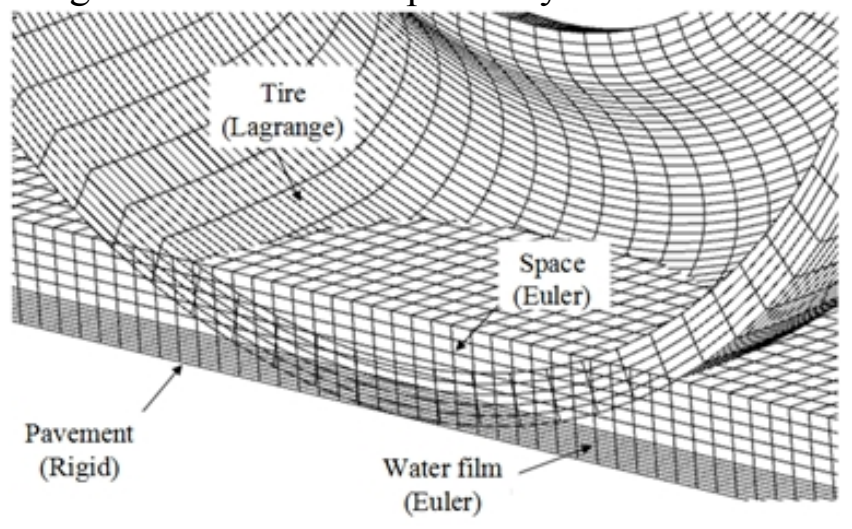

Fig.2 The model of the tire, pavement and water

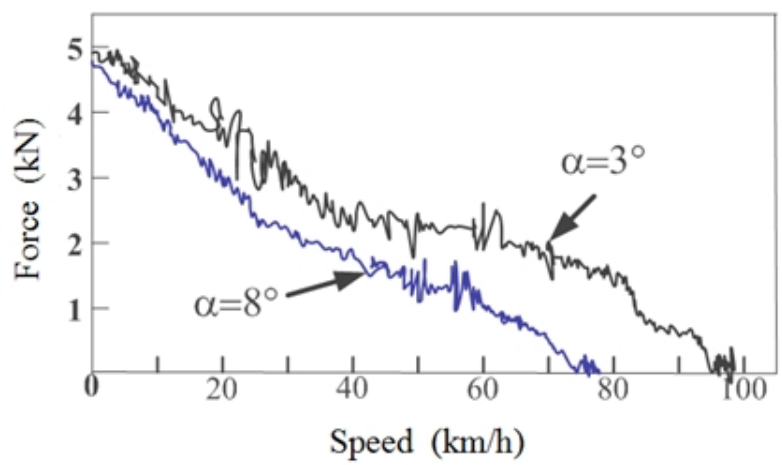

Fig. 3 The relationship between the speed and the contact force of the tire on the pavement with different slopes

The contact force between tire and ground on slope pavement covered with water flow shall, on one hand, overcome the sharing part of load in the reverse direction along the pavement, one the other hand, overcome the dynamic fluid pressure between tire and water flow. Therefore, compared with dry pavement, there is a significant decreasing tending in the contact force between tire and ground on hydroplaning slope pavement. When the acting force of water flow exceeds vertical acting force of tire per se, the tire will separate from the flow completely causing the dangerous condition of complete hydroplaning. Generally, running velocity of automobile on wet pavements does not exceed $100 \mathrm{Km} / \mathrm{h}$. Known from Figure 6 that a slight increase to slope angle may give rise to significant decrease of contract force between pavement and ground where that climbing performances of automobile tire will be significantly reduced. When the slope angle reaches $8^{\circ}$, the critical hydroplaning speed is merely about $75 \mathrm{Km} / \mathrm{h}$. Climbing speeds of automobiles on up slopes shall be limited under $80 \mathrm{Km} / \mathrm{h}$ as possible on wet and rainy days.

\section{Pressure analysis of contract water flow for patterned tire}

The tire with complex patterns running on hydroplaning pavements at a high speed will have certain acting force to the water flow on ground. Fig. 4 below shows pressure distributions of three different patterned tires in running process. (Upward rolling of tire)

As shown in the figure that the overall acting forces to water flow of tires with different patterns in the process of running are ordered: strip pattern $>\mathrm{S}$-shape pattern $>\mathrm{V}$-shape patted. The reason is that S-shape patterned tire and V-shape patterned tire have certain transverse patterns which can not only provided storage space for water but also serve as drainage channel. S-shape patterned tire and $\mathrm{V}$-shape patterned tire therefore impose smaller pressure to water flow than strip patterned tire. And compared with S-shape patterned tire, V-shape patterned tire is exposed to smaller water flow 
pressure because it has certain circumferential patterns which can eliminate water flow pressure to a certain extent.

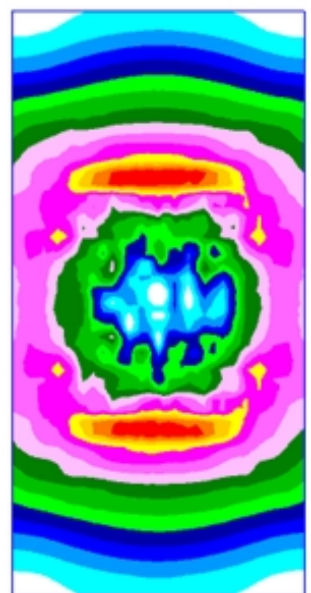

(a) Strip pattern

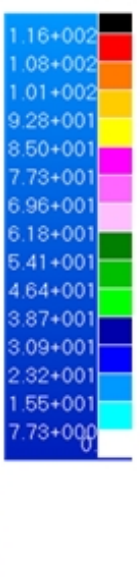

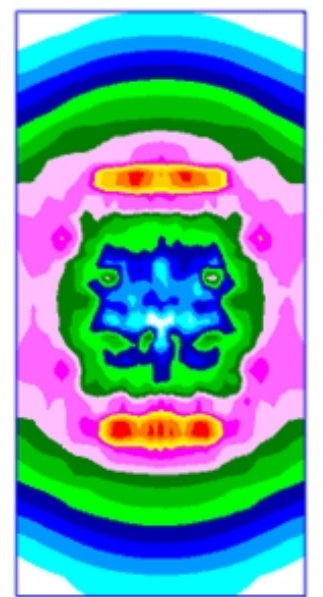

(b) S-shape pattern

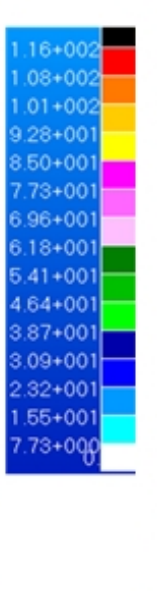

(c) V-shape pattern

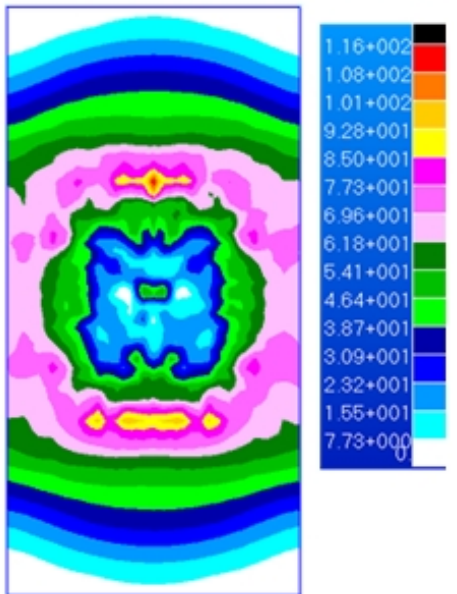

The larger the pressure of water flow at contact area of tire, the smaller the contact force between tire and ground. It can be seen from the above figure that V-shape patterned tire is exposed to the smallest water pressure hence it has the largest contact force. The contact force between strip patterned tire and ground is the smallest and most likely causes the dangerous state of complete hydroplaning under certain circumstances where the tire separates from the ground.

\section{Hydroplaning adhesive force analysis of patterned tire}

When a radial tire is running on hydroplaning pavement, the adhesive force between tire and ground will be gradually reduced, but in a relatively low rate, with increase of speed of the tire due to influences of centrifugal forces and different tread patterns. When the automobile runs at a certain limit speed, the adhesive force of radial tire will reach a certain stable value. If further accelerate, the adhesive force of ground will be sharply reduced and tire starts to slop. When reach a certain speed, the adhesive force is nearly zero where the limit speed on hydroplaning pavement is reached.

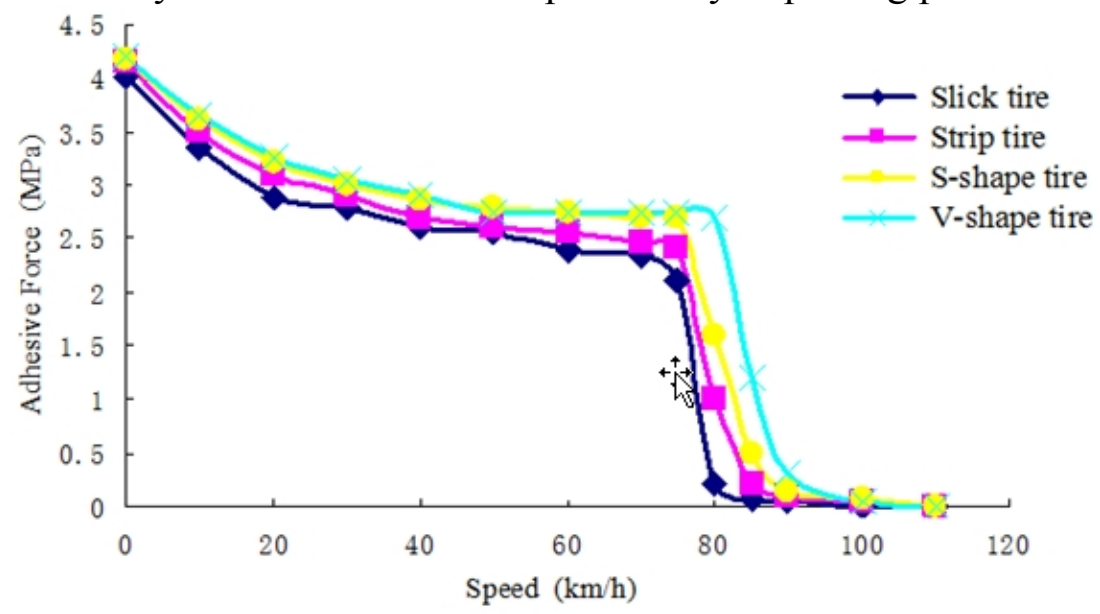

Fig. 5 The diagram of adhesive force changes with speed of four types of tires

Fig. 5 shows the change conditions of contact forces at contact area with speed increase of three types of different patterned tires mentioned above and slick radial tire. It can be seen in the figure that the four different patterned tires have different adhesive force balance points. Tread patterns to some extent reduce hydrodynamic forces of water flow to tire and increase the adhesive force between tire and ground. Amongst these four tires, V-shape patterned tire has the best adhesive performance and the largest stable adhesive value and it also has larger limit speed that other patterned tires. There must be a certain adhesive force between tire and ground to ensure stable controllability of 
automobile. Limit speeds of these four tires studied in this paper are respectively: slick tire $80 \mathrm{~km} / \mathrm{h}$, strip tire $86 \mathrm{~km} / \mathrm{h}, \mathrm{S}$-shape patterned tire $88 \mathrm{~km} / \mathrm{h}$ and $\mathrm{V}$-shape patterned tire $90 \mathrm{~km} / \mathrm{h}$.

\section{Conclusions}

This paper combining hydromechanics, has obtained the theoretical relational expression of the automobile running speed and slope angle by studying force analysis of tire on slope. The 3D infinite element model of tire-slope-water flow is established to compare change rules of tread deformation and contact blotting of tires on horizontal ground and slop ground with a certain angle. At the same time, the contact force changes between automobile tire and ground with running speed changes under two slope angles are simulated, which may forecast tire speeds on wet slope pavements and play a guiding role and provide theoretical significance for further in-depth analysis of climbing performances of automobiles on hydroplaning pavements. The mechanism of dynamic hydroplaning occurred when radial tires run on pavements covered with water flow is studied. The speed difference and contact force difference of tires on wet and dry pavements are compared, and it shows that the faster the automobile runs, the smaller the contact force between tire and ground and the more likely causing hydroplaning state. Moreover, the relation of critical hydroplaning speed is directly proportional to load is obtained based on theories of hydromechanics. The pressure distribution of contact water flow of patterned tire is complex; however, in general, V-shape patterned tire is exposed to small water flow pressure. It is shown in the adhesive change relations with speed changes of tires with different treads on hydroplaning pavements that available limit speed of $\mathrm{V}$-shape patterned tire is relatively larger due to its exposure to smaller water pressure.

\section{References}

[1] H F Yao, Y P Wang, Y C Chen, X Ren, Analysis and Calculation of Dynamic Characteristics for PEV, Sci. Tech. and Eng. 25(2010) 6351-6353. (in Chinese)

[2] Y Li, K Cheng, P Ren, Analysis about Grade Ability of Articulated Tracked Vehicle Base on RecurDyn, Coal Mine Machinery. 7(2011) 93-95. (in Chinese)

[3] J R Cho, W Lee Hong, W S Yoo, A wet-road braking distance estimate utilizing the hydroplaning analysis of patterned tire, Inter. J. for Numerical Methods in Engineering. 7(2007) 1423-1445.

[4] C W Oh, T W Kim, H Y Jeong, K S Park and S N Kim, Hydroplaning simulation for a straight-grooved tire by using FDM, FEM and an asymptotic method, J. of Mechanical Science and Technology. 22(2008) 34-40.

[5] S S Kumar, K Anupam, T Scarpas, C Kasbergen. Study of Hydroplaning Risk on Rolling and Sliding Passenger Car, Procedia - Social and Behavioral Sciences. 53(2012) 1020-1028.

[6] M Y Zang, L P Zhu, Z F Ying, Simulation Analysis of Hydroplaning Characteristics of 3-D Patterned Tire, Science technology and engineering.11(2009) 2999-3008. (in Chinese)

[7] G Cheng, G Q Zhao, Y J Guan, Z L Wang, Study on deflection performance of radial Tire by finite element method, Noise and Vibration Worldwide. 11(2011) 30-35 .

[8] T Okano, M Koishi, A new computational procedure to predict transient hydroplaning performance of a tire, Tire Science and Technology. 1(2001) 2-22 .

[9] N Liu, G Cheng, T He, Velocity analysis of the tire on wet pavement, China Elastomerics. 4(2012) 25-28. (in Chinese) 